\title{
“PONTE PRA TUDO!”: TRANSPOSIÇÃO DIDÁTICA E O ENSINAR DA QUÍMICA
}

\author{
Marcelo Prado Amaral-Rosa ${ }^{1}$ \\ Roniere dos Santos Fenner ${ }^{2}$ \\ Simone Mertins ${ }^{3}$ \\ Carla Melo da Silva ${ }^{4}$ \\ Lorita Aparecida Veloso Galle
}

\begin{abstract}
Resumo: É recorrente o discurso de dificuldade no aprendizado com relaçáo à disciplina de Química. Assim, o objetivo, neste ensaio, é discutir os aspectos principais da teoria da transposiçáo didática de Yves Chevallard no ensinar da Química, visando com isso, aproximaçôes que favoreçam entendimentos referentes à didática da ciência Química no âmbito escolar básico. Acredita-se que a abordagem sobre aspectos didáticos, tendo como "lente" a teoria da transposição didática de Yves Chevallard, apresenta-se como um aporte teórico que pode auxiliar os docentes da disciplina de Química frente às possibilidades e dificuldades encontradas no ambiente escolar contemporâneo.
\end{abstract}

Palavras-chave: transposição didática, ensino, Química.

\section{“BRIDGE TO EVERYTHING!”: DIDACTIC TRANSPOSITION AND THE TEACHING OF CHEMISTRY}

\begin{abstract}
: the discourse of difficulty in learning in relation to the discipline of chemistry is recurrent. Thus, the objective of this text is to discuss the main aspects of the theory of didactic transposition of Yves Chevallard in the teaching of the Chemistry, aiming with this, approaches that favor understandings regarding the didactic of Chemical Science in the basic school scope. It is believed that the approach on didactic aspects, having as a "lens" the theory of didactic transposition of
\end{abstract}

1 Estágio Pós-Doutoral em Educação em Ciências e Matemática (PUCRS).

2 Dr. em Educação em Ciências (UFRGS). Docente UFRGS, campus Litoral Norte.

3 Doutoranda em Educação em Ciências e Matemática (PUCRS).

4 Doutoranda em Educação em Ciências e Matemática (PUCRS).

5 Doutoranda em Educação em Ciências e Matemática (PUCRS). 
Yves Chevallard, presents itself as a theoretical contribution that can be of great value for teachers of the discipline of Chemistry in the face of the possibilities and difficulties encountered in the contemporary school environment.

Keywords: didactic transposition, teaching, chemistry.

\section{CONSIDERAÇÓES PRELIMINARES}

Agora, preste atenção; havendo demonstrado que as coisas náo podem nascer do nada e nem, uma vez nascidas, serem devolvidas de novo para o nada, [...] deixe-me citar outros corpos cuja existência material você deverá admitir, mesmo sendo invisíveis (LUCRÉCIO citado por POZO, CRESPO, 2009, p. 138).

A passagem é o "entrelugar" em que há a possibilidade de acesso e sobrevivência de tudo o que é produzido pelo homem, mas viabilizado para a sociedade, para o ensino do conhecimento tido como necessário à formação de um indivíduo, como também pode ser o que Fernando Pessoa chama de "ponte". Ou ainda, e em outro aspecto apanhado por Lucrécio, o conhecimento, depois de gerado, ingressa em muitas esferas, relaciona-se e é adaptado a vários contextos, tem por natureza a habilidade de não se estagnar apenas no campo científico. A "ponte" tem na escola seus extremos: o ponto de partida e o de chegada, sendo a passagem possível por meio da intermediação do docente, aliado aos recursos didático-pedagógicos de que dispóe.

Antes de prosseguir, cabe esclarecer os motivos que levaram à construçáo da peculiaridade deste trabalho: o título é um verso extraído de um poema de Fernando Pessoa. Percebeu-se na poesia a possibilidade de comunicaçáo (multi)relacional, prazerosa e audaz, pois de acordo com Novalis "o poético é o autêntico real absoluto. [...]. Quanto mais poético, mais verdadeiro" (citado por PESSOA, 1986, [s.p.]). De tal modo, a imersão nos poemas pessoanos fez com que fossem sendo reveladas aproximaçóes que comunicam outras formas de conviver, conhecer e pensar nas relaçóes interpessoais, estando assim, de acordo com as diversificadas forma de conhecer, comunicar e vivenciar das experiências didáticas de sala de aula. Assim, o poema com o qual se estabelece relação aqui é Saudação a Walt Whitman, de junho de 1915 (PESSOA, 2008a, p. 106). Pessoa, nesse poema, faz uma homenagem ao poeta norte-americano, considerado o pai dos versos livres. Para Pessoa, Whitman é a "ponte" para todo e qualquer pensamento, sendo isso evidenciado no próprio poema com a passagem "[...] Minha senha? Walt Whitman!/ [...]/Sou EU [sic], um universo pensante de carne e osso, querendo passar,/ [...]" (Ibid., p. 102). De tal modo, a conexão direta entre o poema e o trabalho é o sentido conceitual entre a "ponte" e o conceito de transposiçáo didática de Chevallard (2005), uma vez que segundo esse autor, os conteúdos específicos da disciplina de Química só podem ser ensinados sofrendo deformaçôes.

No campo da educação, pesquisas debruçadas sobre a transformação do conhecimento, produzido pela ciência com finalidades educacionais, têm sido realizadas de forma recorrente (LOPES, 1997; MARANDINO, 
2004; BROCKINGTON, PIETROCOLA, 2005; POZO, CRESPO, 2009; PIETROCOLA, 1999; LEIVAS, CURY, 2009; MONTEIRO, 2003), inclusive ganhando destaques em periódicos de conceituada circulação nacional ${ }^{6}$. Assim, evidencia-se a preocupação de pesquisadores a respeito das maneiras como os conhecimentos produzidos pela ciência têm acessado os bancos escolares.

Diante do sucinto contexto supra exposto, o objetivo neste texto é discutir os aspectos principais da teoria da transposição didática de Yves Chevallard, no ensinar de Química, visando com isso, aproximaçóes que favoreçam entendimentos referentes à didática da ciência Química no âmbito escolar básico.

\section{TRANSPOSIÇÃO DIDÁTICA E O ENSINO DA QUÍMICA}

No âmbito das Ciências, percebe-se que nem sempre ocorre aproximar os conteúdos à significância da realidade do aprendiz. Desse modo, existe no ensino fundamental e médio, a noção de que os estudantes aprendem cada vez menos e apresentam um crescente desinteresse pelos estudos nos quais estão envolvidos ao longo de cada etapa escolar, desconectando-se do sentido de cidadania inerente à educação. Essa situaçáo causa, entre os professores de Ciências, uma crescente sensação de impotência, frustração e passividade no ato pedagógico, diante do contestado sucesso em sala de aula (POZO; CRESPO, 2009). Sobre isso, Leivas e Cury (2009), e também Pozo e Crespo (op. cit.), relatam que o problema do ensino de conteúdos específicos das áreas das Ciências Naturais é o distanciamento entre os conteúdos abordado em sala de aula, a realidade do estudante e as origens do saber em questão, acarretando mudanças didáticas no sentido lato sensu, elencadas por Chevallard $^{7}$ (2005).

De acordo com Pozo e Crespo (op. cit.), a crise das Ciências não é novidade tendo em vista a historicidade da civilização e seus mitos fundadores ${ }^{8}$. De acordo com os mesmos autores, "o desajuste entre a ciência que é ensinada e os próprios alunos é cada vez maior, refletindo uma autêntica crise na cultura educacional (Ibid., p. 19, grifo do autor). Convém aqui uma sucinta definição sobre a expressão crise, pois o uso da mesma nas instituiçóes educacionais é realizado de maneira generalista,

6 Periódicos como por exemplo Química Nova (seção Educação), Química Nova na Escola e Investigaçôes em Ensino de Ciências são apenas alguns exemplos de veículos de divulgação da ciência nacional que normalmente divulgam pesquisas com temáticas que envolvem transposição didática.

7 Especificaçôes pertencentes à teoria da transposição didática de Yves Chevallard não serão abordados aqui. Entretanto, sinteticamente, o sentido lato sensu para Chevallard engloba o percurso de modificação desde a origem científica do conhecimento até os bancos escolares.

8 De acordo com o Gênese, após criar tudo o que há na Terra, Deus advertiu Adão e Eva sobre a árvore da sabedoria e sobre os riscos de tentar entender o porquê das criaçóes divinas. No entanto, eles não escutaram e provaram do conhecimento, estando assim, a crise do conhecer no motivo principal da expulsão do homem do Paraíso (POZO; CRESPO, op. cit.). Ainda, Fernando Pessoa no poema Ulisses clarifica o que vem a ser o mito e as conexóes com a sociedade: "O mito é o nada que é tudo" (PESSOA, 2008b, p. 41). 
sendo possível observar, conforme Stecanela (2010, p. 44) "que a expressão está relacionada às especificidades de uma forma particular de educaçáo, normalmente associada ao seu modelo escolar". Chevallard reconhece a crise por que passa a Ciência e aproxima-se da sensaçáo instalada no professorado, uma vez que ciência é uma palavra que "[...] a cultura náo compreende mais muito bem; por essa razão não sabe mais se convém utilizar com referência ou desprezo; diante da qual vemos hesitar entre a comoção, a indiferença e a atribuição de importância [...]" (apud LEITE, 2007, p. 51). Sobre esse aspecto, de acordo com Lopes (1997, p. 564), "o maior problema em questão é a forma de apropriação do conhecimento pela escola, o processo da transposição didática que retira do conceito sua historicidade e sua problemática”. Ainda, de acordo com Chevallard (2005), a concepção da transposição didática está no cerne da crise, uma vez que todo conhecimento ao sofrer transformaçóes sociais é envolto em um determinado grau de alguma crise [passageira ou não]. Segundo Chevallard (2005), a noosfera ${ }^{9}$ é por excelência o locus de conflitos e negociaçóes nem sempre harmônicos, voltando-se, geralmente, para os saberes a ensinar, embora os motivos das crises do sistema educacional não estejam necessariamente vinculados aos saberes a ensinar, mas aos métodos didáticos.

Sobre a aprendizagem por parte dos estudantes no que diz respeito à Ciência que lhes é ensinada, Pozo e Crespo (2009) sáo categóricos ao afirmar que os mesmos não aprendem; e ilustram essa posição por meio da exposição de dificuldades no uso de estratégias de raciocínio e soluçóes de problemas característicos do trabalho científico, como por exemplo na "fraca generalização dos procedimentos adquiridos para contextos novos" (Ibid., p.17) ${ }^{10}$.

As dificuldades apresentadas no quadro 2 evidenciam situaçôes comuns dentro do domínio denominado por Pozo e Crespo (2009), de conteúdos procedimentais do currículo de Ciências; ainda, tais dificuldades se evidenciam principalmente na resoluçáo de problemas, na qual os estudantes ao em vez de adotarem uma postura reflexiva e ativa diante dos mesmos, tendem a apresentar um comportamento incompatível com as finalidades da ciência, encarando-os como exercícios rotineiros de simples execução. Pozo e Crespo (op. cit.), são enfáticos sobre as consequências de transposiçóes precárias do saber sábio para o saber ensinado, listando atitudes e crenças inadequadas mantidas pelos estudantes com relação à aprendizagem das Ciências da Natureza, algumas delas, a saber: i) aprender ciência consiste em repetir da melhor maneira possível o que o professor explica durante as aulas; ii) para aprender ciência é melhor não tentar encontrar suas próprias respostas, mas aceitar o que o professor e o livro didático dizem, porque isso está baseado no conhecimento científico; iii) o conhecimento científico é muito útil para trabalhar

9 Este conceito não é diretamente detalhado aqui, entretanto, de forma sintética é a responsável por [tentar] manter em equilíbrio a escola e a sociedade.

10 Para maiores detalhes sobre as dificuldades dos estudantes apresentadas por Pozo e Crespo (2009) ver quadro Dificuldades na aprendizagem de procedimentos no caso dos problemas quantitativos (p.17). 
no laboratório, para pesquisa e para inventos, mas não serve praticamente para nada na vida cotidiana; e iv) a ciência proporciona um conhecimento verdadeiro e aceito por todos.

No caso específico do ensino da Química, o principal objetivo, dentro da educação básica está centrado, segundo Pozo e Crespo (2009, p. 139) "no estudo da matéria, suas características, propriedades e transformaçôes a partir da sua composição íntima (átomos, moléculas, etc.)”. Em síntese, a pretensão é ensinar o estudante "a compreender, interpretar e analisar o mundo em que vive, suas propriedades e suas transformaçóes" (Ibid.), logo, pode-se afirmar que a Química é a ciência que tem como um de seus objetivos mostrar a intimidade do mundo (RETONDO; FARIA, 2008). Por meio do objetivo geral da Química na educaçáo básica, percebe-se o imbricamento relacional com a teoria de Chevallard (2005), pois para desvelar a intimidade do mundo, por vias da Química, é preciso considerar as deformaçóes do objeto do saber, desde sua produçáo na academia até sua entrada nas escolas.

De acordo com Lopes (1999) a constituição do conhecimento escolar "ocorre no embate com os demais saberes sociais, ora afirmando um dado saber, ora negando-o, ora contribuindo para sua construção, ora se configurando como obstáculos sua elaboração por parte dos alunos” (p. 104). De acordo com Chevallard (op. cit.) os "embates" ocorrem na noosfera, pois é onde ocorre a interação entre o sistema didático e o ambiente social, ocorrendo a transformação do objeto de saber a ensinar em um objeto de ensino. Ainda, convém esclarecer aqui que Lopes (1997, 1999), defende o uso da terminologia mediação didática em substituição a transposição didática. A autora argumenta que o termo transposição didática remete à associação a uma mera reprodução, a um "movimento de transportar de um lugar a outro, sem alteraçôes" (p. 208). Lopes (1999) prefere o termo mediação didática no sentido dialético, partindo de mediaçôes contraditórias entre a realidade e relaçóes complexas, não imediatistas, configurando-se em "um profundo sentido de dialogia" (p. 209), em contrapartida ao "sentido genérico, ação de relacionar duas ou mais coisas, de servir de intermediário ou ponte [...]" (p. 208, grifo nosso). Entretanto, existe a concordância com Leite (2007) a respeito dessa [e de outras] terminologia(s) alternativa(s) que "apesar de pertinentes, não se desdobram em teorias significativamente diferenciadas" (p. 48). Assim, concordando com Leite (2007), decidiu-se por manter neste trabalho a terminologia cunhada por Chevallard (op. cit.) de transposição didática, por acreditar que se um observador qualquer, ao cruzar uma determinada ponte, e chegar ao outro lado da margem, terá alterado seu olhar sobre todas as coisas que o rodeia no ambiente. Ao ocorrer isso, as observaçōes/percepçóes do observador sobre o ambiente, terão sofrido deformaçóes, transformando-se assim, em um ambiente diferente do até então ambiente que existia antes do transladar. 
Pozo e Crespo (2009) expóem as dificuldades da aprendizagem da Química ${ }^{11}$, principalmente nos níveis fundamental e médio da educaçáo, justificando que as mesmas apresentam suas origens na gama de conceitos com alto nível de abstração, linearidade e interdependência ao longo da educação básica, e. g., forças intermoleculares e geometria molecular. Sirhan (2007), por sua vez, explica a situação de dificuldade de compreensão da Química por essa ser uma ciência de elevado grau de abstração e conceituação, exigindo assim, dedicação e empenho daqueles que necessitam/desejam aprendê-la. Ainda, na trajetória da cadeia de escolarização, o estudante depara com a introduçáo de teorias diferentes para explicar um mesmo ponto curricular de estudo, e. g., as teorias de ácido-base, o que provoca a elevação do nível de dificuldade na assimilação e aplicação das teorias. Com base nessas características, Pozo e Crespo (2009) consideram que estudar Química, principalmente no nível médio, envolve um nível de abstração de elevado grau, conferindo assim a "abstraçáo sobre a abstração" (2009, p. 141).

Para Chevallard (2005) o ponto fundamental da didática é a relação entre o saber sábio e o saber ensinado. Assim, segundo Pozo e Crespo (op. cit.) a compreensão da Química envolve mudanças na lógica organizacional do estudante sobre as concepçóes que ele próprio formula, baseadas em aspectos perceptivos. Pessoa (2008b), considera essa forma de ver o mundo como sendo uma espécie de inocência primitiva ${ }^{12}$ que náo está baseada em crenças e nem tão pouco em explicaçóes racionais, uma vez que "O que nós vemos das coisas são as coisas./ Por que veríamos nós uma coisa se houvesse outra?/ Por que é que ver e ouvir seria iludirmo-nos/ Se ver e ouvir são ver e ouvir?” (Ibid., p. 63). A superação dessa visão de mundo é essencial para a aprendizagem da Química de modo que conceitos (e.g., orbitais, números quânticos, entre outros tantos) "não precisem ser entes reais, senão que são aceitos como construçóes abstratas que ajudam a interpretar a natureza da matéria e suas propriedades" (POZO; CRESPO, op. cit., p. 142).

Com relação aos exemplos dos conceitos de orbitais e número quânticos, Lopes (1997), exemplifica a transposição didática em Química justamente com o tratamento conferido à estrutura eletrônica. De acordo com a autora, o conceito de orbital, contemplado nos livros didáticos de Química, banalizou-se a ponto de distanciar-se completamente do constructo inicial, o qual rompia com concepçóes realistas e de continuidade macroscópica da ciência, sendo transmitido ["didaticamente"] de forma realista e esquemática. Já em relação à distribuição eletrônica, essencial para a compreensão da estrutura molecular e princípios de

11 Ver Quadro 6.3 Algumas dificuldades na aprendizagem da quimica (POZO; CRESPO, op. cit., p. 141).

12 Bertrand Russell considera tal visão como sendo realismo ingênuo. De acordo com esse autor todos começamos no mundo com essa visão das coisas, "[...] isto é, a doutrina de que as coisas são aquilo que parecem ser. Achamos que a grama é verde, que as pedras são duras e que a neve é fria. Mas a física nos assegura que o verdejar da grama, a dureza das pedras e a frieza da neve não são o verdejar da grama, a dureza das pedras e a frieza da neve que conhecemos em nossa experiência própria, e sim algo muito diferente" (citado por MLODINOW, 2009, p. 14). 
ligaçôes entre elementos/moléculas, passou a ser visto na escolarização de nível médio "[...] como uma espécie de jogo: conhecidas as regras de preenchimento dos orbitais, nada mais fácil do que neles colocar os elétrons" (LOPES, 1997, p. 564, grifo do autor). Ainda, conforme a mesma autora, tal didatização dos conceitos da Química se aproxima da situação apresentada para o conceito de distância de Chevallard e Joshua (CHEVALLARD, 2005), visto que, somente o resultado é tratado na escola, deixando o processo histórico da ciência à margem do ato de ensino. Sobre isso, Pozo e Crespo (2009) consideram que tal situaçáo "[...] não deve causar estranheza [...]" (p. 145), pois a origem histórica dos conceitos da ciência apresenta evoluçóes temporais complexas, não servindo ao imediatismo proposto para o saber escolar, que no formato atual, auxilia a condição de reforço sobre as concepçôes intuitivas/perceptivas dos aspectos do mundo que rodeiam o estudante.

O ponto central da transposiçáo didática para o docente é a questão de que os conteúdos contidos nos livros didáticos e em outros materiais de apoio pedagógico ao ensino são deformaçôes necessárias para que o processo educacional na escola seja efetivado (CHEVALLARD, 2005). Desse modo, o saber sábio se distancia cada vez mais das suas raízes acadêmicas e aqui é preciso considerar outra contribuição de Chevallard (op. cit.): a vigilância epistemológica. No processo de vigilância epistemológica, há um inevitável e necessário distanciamento entre o saber sábio e o saber ensinado, devido às diversas e sucessivas deformaçôes que o saber sofre com o passar do tempo. Nessa relação de afastamento entre o saber da ciência e o saber da escola, a noosfera torna viável o equilíbrio entre o sistema didático e o entorno social, entretanto, a compatibilidade é dependente da relação de distanciamento equilibrado do saber ensinado ao saber sábio e ao "saber banalizado" (Ibid., p. 30). "O saber ensinado se gasta" (Ibid., grifo do autor, tradução nossa). Quando o saber ensinado se afasta por demasiado do saber sábio ocorre o envelhecimento biológico, sendo o ensino questionado devido à obsolescência diante do contexto social. Em contraponto, simultaneamente, a aproximaçáo demasiada do saber ensinado do saber banalizado, causa o envelhecimento moral do saber, causando assim, críticas sociais sobre a função da escola. De tal maneira, a noosfera é a responsável por selecionar os conteúdos do saber, estabelecendo a compatibilidade necessária para o saber ensinado (CHEVALLARD, 2005; LEITE, 2007).

\section{CONSIDERAÇÓES FINAIS}

Com vistas ao exposto, ao abordar aspectos do ensino da Química relacionados com a teoria da transposição didática de Chevallard (op. cit.), evidencia-se que: i) de modo geral, Chevallard (op. cit.) pretende que os saberes presentes no ensino não sejam simplórias transformaçóes de saberes extraídos dos contextos de pesquisas científicas com a finalidade de apreensão pelos estudantes; ii) a teoria em questáo oferece elementos que visam à compreensão do processo de didatização do conhecimento no âmbito escolar. Logo, a mesma contribui para o entendimento da prática docente por se relacionar diretamente ao campo da didática, considerando 
que essa é influenciada por aproximaçóes e distanciamentos diversos entre setores escolares, econômicos, políticos e culturais.

É notório que a educação é um processo de construção de pontes entre o mundo e a escola, em regime de inter/intradependência. De tal modo, a sociedade tem por dever incluir as transformaçóes, de toda ordem, independentemente da fonte de onde sejam provenientes. Dessa maneira, acredita-se que a teoria da transposiçáo didática de Chevallard é considerada constantemente nas práticas docentes e devido a isso, faz-se importante a apropriaçáo dos conceitos que estão englobados nessa teoria, visando o aprimoramento didático no cotidiano do ensino de Química/ ensino de ciências. O aprimoramento didático docente, frente às práticas cotidianas de sala de aula, tem como consequência direta uma formaçáo sólida do indivíduo voltada à cidadania e ao contexto que o circunda e/ou permeia, uma vez que para Chevallard a relação professor-estudante é decorrência da interface sociedade-escola regulada pela noosfera, conferindo a teoria da transposiçáo didática um fundamental recurso para o entendimento do processo formativo escolar de qualidade.

Diante das consideraçóes acima, conscientes de que este trabalho é apenas o começo de discussóes e reflexóes, procura-se mais uma vez, em Fernando Pessoa, as palavras corretas [se é que existem as palavras corretas] para endossar o que foi exposto neste texto e visualizando as possibilidades que vão emergindo: "Há uma vaga brisa./ Mas a minh'alma está com o que vejo menos/ [...]/ E, sem que nada se altere,/Tudo se revela diverso" (PESSOA, 2008a, p. 61). Assim, há o entendimento de que a abordagem sobre aspectos didáticos, tendo como "lente" à teoria da transposição didática de Yves Chevallard, apresenta-se como um aporte teórico que pode auxiliar os docentes de Química frente às possibilidades e dificuldades encontradas no ambiente escolar contemporâneo.

\section{REFERÊNCIAS}

BROCKINGTON, Guilherme; PIETROCOLA, Maurício. Serão as regras da transposição didática aplicáveis aos conceitos de Física moderna? Investigaçóes em Ensino de Ciências, v.10(3), p. 387-404, 2005.

CHEVALLARD, Yves. La transposición didáctica: del saber sábio al saber enseñado. [Título original: La transposition didactique. Du savoir savant au savoir enseigné]. Traducción de Claudia Gilman. Buenos Aires: Aique, 2005.

LEITE, Miriam Soares. Recontextualização e transposiçáo didática: introdução à leitura de Basil Bernstein e Yves Chevallard. Araraquara, SP: Junqueira\&Marin, 2007.

LEIVAS, José Carlos Pinto; CURY, Helena Noronha. Transposição didática: exemplos em educação matemática. Educaçáo Matemática em Revista - RS, ano 10, n.10, v.1, p. 65-74, 2009.

LOPES, Alice Ribeiro Casimiro. Conhecimento escolar em Química: processo de mediação didática da ciência. Química nova, 20(5), p. 563-568, 1997. 
LOPES, Alice Ribeiro Casimiro. Conhecimento escolar: ciência e cotidiano. Rio de Janeiro: EdUERJ, 1999.

MARANDINO, Martha. Transposição ou recontextualizaçãa? Sobre a produção de saberes na educação em museus de ciências. Revista Brasileira de Educaçáo, n.26, p. 95108, maio/ago., 2004.

MLODINOW, Leonard. $\mathbf{O}$ andar do bêbado: como o acaso determina nossas vidas. Tradução Diego Alfaro. Rio de Janeiro: Zahar, 2009.

MONTEIRO, Ana Maria Ferreira da Costa. A história ensinada: algumas configuraçóes do saber escolar. História \& Ensino, Londrina, v.9, p. 37-62, out., 2003.

PESSOA, Fernando. Poemas de Álvaro de Campos: obra poética IV. Organização, introdução e notas Jane Tutikian. Porto Alegre, RS: L\&PM, 2008a.

. Poemas de Alberto Caeiro: obra poética II; organização, introdução e notas Jane Tutikian. Porto Alegre: L\&PM, 2008b.

. Cartas de amor. Rio de Janeiro: tecnoprint, 1986.

PIETROCOLA, Mauricio. Construção e realidade: o realismo científico de Mário Bunge e o ensino de ensino de ciências através de modelos. Investigaçóes em Ensino de Ciências, v.4(3), p. 213-227, 1999.

POZO, Juan Ignácio; CRESPO, Miguel Ángel Gómez. A aprendizagem e o ensino de ciências: do conhecimento cotidiano ao conhecimento científico. Tradução Naila Freitas. 5 ed., Porto Alegre: Artmed, 2009.

RETONDO, Carolina Godinho; FARIA, Pedro. Química das sensaçóes. Campinas, SP: Editora Átomo, 2008.

SIRHAN, Ghassan. Learning difficulties in chemistry: an overview. Journal of Turkish Science Education, v.4(2), sept., 2007.

STECANELA, Nilda. Jovens e Cotidiano: trânsitos pelas culturas juvenis e pela escola da vida. Caxias do Sul: Educs, 2010. 